\title{
现代建筑结构检测与加固施工技术
}

间涁涁

\author{
宁夏建筑材料产品质量监督检验站有限公司 \\ DOI:10.18686/bd.v2i1.1165
}

[摘 要] 现阶段, 在我国社会经济快速发展的今天, 对建筑工程结构检测又提出了新的要求, 使得建筑工程在结构检测过程 中逐渐研发出一些新型检测技术。基于此, 本文就对现代建筑结构的检测方法进行分析, 并提出针对性的建筑结构加固施工 技术, 以期为建筑工程的施工提供参考依据。

[关键词] 现代建筑; 建筑结构检测;加固施工技术

建筑结构加固施工技术是保证建筑工程质量的基础, 对建筑工程的快速发展具有重要意义㧫。但是现阶段,我国 建筑工程在发展过程中逐渐出现一些质量问题, 严重制约 了建筑工程的快速发展。基于此,本文就对现代建筑结构检 测方法进行总结, 并对建筑结构的加固施工技术进行阐述, 以期提升现代建筑结构质量, 推动建筑工程行业实现快速 发展。

\section{1 现代建筑结构检测方法分析}

1.1 建筑工程结构的砳体结构检测技术分析

砌体结构是建筑工程结构中的重要组成部分, 对建筑 工程整体结构稳定性起到至关重要的作用 ${ }^{[2]}$ 。因此, 建筑企 业相关人员需要提高对砌体结构检测工作的重视, 使用砂 浆片剪切法、回弹法等众多方法对建筑工程的硼体结构进 行检测,将砌体结构中存在的问题进行解决, 保证建筑工程 砌体结构质量。通常情况下,建筑企业相关人员对建筑工程 砌体机构进行检测主要包含直接检测和间接检测方法两 种, 其中直接检测方法主要是指相关施工人员在砌体检测 过程中使用检测设备对砌体结构的强度进行直接检测, 然 后将检测结果整理成数据,通过数据直接将砌体结构质量、 砌体材料质量等方面内容反映出来, 方便工作人员及时了 解建筑工程砌体中存在的问题, 保证建筑工程砌体结构质 量。此种方法在使用过程中由于施工人员将检测设备直接 接触到建筑工程砌体结构, 所以对建筑工程砌体结构会产 生严重的损坏,在砌体结构检测过程中不会被经常使用。而 建筑工程砌体结构的间接检测方法主要是指相关施工人员 在施工中先对砌体结构中所使用的砂浆材料进行检测, 并 将检测结果整理成相应数据, 然后再使用公式推算法对建 筑工程砌体结构参数进行推算, 让施工人员了解建筑工程 砌体结构。此种方法在使用过程中无法将建筑工程砌体结 构准确检测出来,所检测的结果也带有一定的误差,但是建 筑工程砌体结构间接检测方法不是直接对砌体结构进行测 量, 所以对建筑工程砌体结构质量的影响程度较小, 在建筑 工程砌体结构检测工作中被广泛使用。

1.2 建筑工程混凝土结构的检测技术分析

混凝土是建筑工程中的基础材料, 是建筑工程顺利开
展的基础[1]。但是现阶段,我国建筑工程在混凝土结构施工 过程中还存在一些问题, 造成建筑工程施工质量严重下降, 面对此种情况, 建筑企业要想保证工程质量就需要提高对 建筑工程混凝土结构检测工作的重视, 对以往建筑工程混 凝土结构检测技术进行完善, 将建筑工程混凝土结构中存 在的问题进行解决, 提高建筑工程混凝土结构质量, 推动建 筑工程实现快速发展。通常情况下, 建筑工程相关施工人员 在建筑混凝土结构检测中所使用的检测技术主要包含以下 几种: 一方面, 建筑工程混凝土结构检测过程中使用回弹法 无损检测技术, 此种方法的使用可以深人反映混凝土质量, 弥补一般检测过程中只能对混凝土表层质量检测的不足情 况, 可以提高建筑混凝土强度的测试精度 ${ }^{[4]}$ 。在通常情况下, 建筑工程中使用的混凝土检测方法主要是单一法, 但是单 一法在检测过程中经常会受到其他外界因素的影响, 造成 检测结果存在误差, 超声回弹综合法的使用就会避免此种 情况, 并且随着混凝土强度的增长, 超声回弹值也会逐渐上 升, 当建筑混凝土表层水分减少后, 超声回弹值就会升高, 从 而明确反映出混凝土强度, 为施工监测人员提供方便, 提高 建筑工程混凝土检测质量。另一方面, 建筑工程混凝土结构 检测中使用钻心法, 此种方法在使用过程中需要相关人员 对建筑工程混凝土芯进行合理钻取, 然后再将建筑工程的 混凝土强度进行检测, 合理测量出混凝土结构的强度, 此种 混凝土检测方法在使用过程中对建筑工程的影响程度小, 准确性高, 所以在建筑工程混凝土检测工作中被广泛进行 使用。

1.3 建筑工程钢结构检测技术分析

现阶段, 由于钢结构具有轻质量、抗震性等特点, 可以保 证建筑物在发生地震时不会出现坡塌情况, 所以在建筑工 程中被广泛进行应用。而钢结构一旦使用不当就会发生锈 蚀等情况, 因此, 建筑企业相关人员需要对建筑工程钢结构 进行检测工作 ${ }^{[5]}$ 。建筑工程钢结构检测工程主要是指相关人 员对建筑工程钢筋等构成元件进行质量、性能等方面内容 的检测, 在钢结构检测过程中最常使用的检测技术主要包 含射线检测技术、锈蚀检测技术等等。相关人员在进行钢结 构检测过程中需要对钢结构的各个组成元件的性能进行动 
力检测, 从而将钢结构中存在的问题及时查找出来, 并进行 解决,保证建筑工程钢结构质量。

\section{2 建筑工程机构的加固施工技术分析}

2.1 建筑工程砌体结构的加固施工技术分析

现阶段, 施工人员在建筑工程中砌体结构进行加固的 施工技术主要包含加大截面加固法、扶壁柱加固法、外包钢 加固法、钢筋水泥砂浆加固法等等, 问在众多加固施工方法 中最常使用的加固施工技术就是加大截面加固法, 此种方 法在使用过程中需要相关人员对建筑工程砌体结构中的各 个砌体角部进行 “打掉”处理, 然后再使用针对性的砌体结 构加固施工技术对砌体结构进行加护保护, 从而提高建筑 工程的承载能力, 提高建筑结构的稳定性, 保证建筑工程施 工质量。

\section{2 建筑工程混凝土结构的加固施工技术分析}

现阶段, 建筑工程混凝土结构的加固施工技术主要包 含预应力法、置换混凝土加固法等等,这些加固施工方法在 使用过程中需要针对具体的混凝土结构进行选择, 可以在 建筑混凝土结构中使用植筋技术, 在建筑工程混凝土结构 中植人钢筋对混凝土结构进行加固, 这种加固方法所使用 的成本少, 技术要求低, 还可以将建筑工程混凝土结构强度 低等缺陷问题进行解决, 从而提高建筑工程混凝土结构强 度, 保证混凝土结构的稳定性, 推动建筑工程的快速发展。与 此同时, 相关施工人员可以对建筑工程进行混凝土浇筑作 业, 并在混凝土浇筑作业过程中保证混凝土浇筑的连续性, 避免混凝土浇筑过程中出现厚度不均匀的情况, 保证混凝 土浇筑质量,提高建筑工程结构稳定性。

2.3 建筑工程钢结构的加固施工技术分析

通常情况下, 建筑工程相关人员在对钢结构进行加固 施工过程中所使用的加固施工技术主要包含加大构件截 面、加强钢结构连接加固等技术,但是在众多加固施工技术 中最经常使用的就是加大构件截面技术, 此技术在使用过 程中主要是将钢结构的钢梁、钢柱等方面构件进行焊接, 从 而保证这些构件的稳定性，提高建筑工程的整体稳定性 [] 与此同时,钢结构在使用过程中需要避免与水接触,所以使 用人员需要在加强建筑工程的防水技术, 避免钢结构发生
腐蚀,保证钢结构质量。

2.4 建筑工程的裂㖓修补施工技术分析

建筑工程投人使用后, 在长时间的使用过程中就容易 产生墙体、地面裂缝问题,使得建筑工程的安全稳定性严重 下降。面对此种情况,建筑工程相关人员就需要对加强对裂 缝的修补工作, 将建筑工程中的裂缝问题进行解决, 具体可 以从以下几个方面展开:一方面,建筑工程相关负责人需要 对地面、墙体裂缝出现的原因进行查找, 并根据原因制定针 对性的修补措施, 将裂㖓问题及时解决, 保证建筑工程质量。 另一方面, 建筑工程相关负责人再完成建筑工程修补工作 之后, 需要对建筑工程继续进行加固作业, 并在加固作业过 程中使用碳化的方式对建筑工程墙体、地面中的裂缝进行 第二次修补,保证建筑工程结构稳定性。

\section{3 总结语}

总而言之, 在我国建筑行业市场竞争日益激烈的今天, 建筑企业要想保证自身在市场上的竞争力, 就需要创新建 筑结构检测技术, 对建筑结构中存在的质量问题及时解决, 并严格按照建筑工程施工要求对建筑结构进行加固施工技 术, 提高建筑结构的牢固性,帮助建筑工程企业实现经济效 益最大化,从而推动我国建筑工程实现可持续发展。

参考文献:

[1] 赵晨光. 浅谈现代建筑结构检测与加固施工技术 [J].江西建材,2016,(2):80-80,86.

[2] 董启军. 浅谈现代建筑结构检测与加固施工技术 [J].建材与装饰,2016,(12):73-74.

[3] 张茹评. 现代建筑结构检测与加固施工技术探微 [J].建材发展导向(上),2017,15(6):12-13.

[4]王霆. 现代建筑结构检测与加固施工技术分析 [J]. 绿色环保建材,2016,(08):164+166.

[5]盖玉刚.浅述建筑结构检测与加固施工技术 [J].门 窗,2015,(07):104.

[6]沈洪.浅谈现代建筑结构检测与加固施工技术 [J]. 商品与质量,2016,(33):80-80.

[7]李晓东.现代建筑结构检测与加固施工技术 [J].绿 色环保建材,2017,(04):117. 